\title{
Vaccine against SARS-CoV-2: Challenges and considerations
}

\author{
Ruchi Chaube ${ }^{1 *}$
}

\begin{abstract}
It is essential to consider challenges previously faced and addressed while developing a vaccine against severe acute respiratory syndrome coronavirus 2 (SARS-CoV-2). Considering the severity of the health crisis that SARS-CoV-2 has caused worldwide, and with so little known about the virus, our focus should be drawn towards approaches that can bring better development outcomes in a relatively short period of time. This commentary discusses the use of nucleic acid (deoxyribonucleic acid and ribonucleic acid) vaccines against viral infections and pandemic-like settings. The potential advantages of the nucleic acid vaccines over conventional vaccines are presented, and the nucleic acid vaccines currently in development against viral infections and the challenges these vaccines face entering clinical trial are discussed.
\end{abstract}

This work is licensed under a Creative Commons Attribution 4.0 International License.

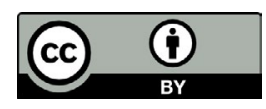

Affiliation

${ }^{1}$ Regulatory Operations and Enforcement Branch, Health Canada, Edmonton, $\mathrm{AB}$

*Correspondence: ruchi.chaube@canada.ca

Suggested citation: Chaube R. Vaccine against SARS-CoV-2: Challenges and considerations. Can Commun Dis Rep 2021;47(3):128-31. https://doi.org/10.14745/ccdr.v47i03a01

Keywords: vaccine, SARS-CoV-2, nucleic acid

\section{Introduction}

A novel coronavirus, severe acute respiratory syndrome coronavirus 2 (SARS-CoV-2), causing coronavirus disease 2019 (COVID-19), entered the human population and rapidly spread around the world in the early months of 2020, causing a global pandemic. This pandemic, as defined by the World Health Organization, is "an epidemic occurring worldwide, or over a very wide area, crossing international boundaries and usually affecting a large number of people" (1), led the scientific and medical communities to initiate serious efforts to limit the wave of viral spread by developing preventative vaccines.

A vaccine (or vaccines) against SARS-CoV-2 would help develop community immunity against the virus and thus prevent the spread and recurrence of the disease at the population level. There has been a surge in vaccine candidates since the pandemic started; however, vaccine protection from SARS-CoV-2 hinges on two questions: first, how soon a vaccine can be made available for use; and second, will the vaccine(s) be protective enough to completely prevent the further spread of the virus. While the first point is temporal and, at present, we are much ahead in the game with respect to COVID-19 vaccines, the second point is fundamental to vaccine development defining a strong and lasting immunological response.

In the past few decades, there has been rapid spread of numerous severe viral infections, including human immunodeficiency virus (HIV), influenza A, severe acute respiratory syndrome (SARS), Ebola and Zika. These infections have necessitated the rapid development and comprehensive distribution of vaccines; however, the development of these vaccines has proven to be extremely difficult. In addition, many of these viruses represent zoonoses (zoonotic diseases), increasing the risk of introducing a virus with completely new immunogenic properties into the human population. Furthermore, it is impossible to predict the characteristics of these viruses, the severity of the diseases they might induce and the scope of the outbreaks they can cause. For example, influenza A virus/H1N1 led to a phase 6 pandemic alert in 2009 but caused relatively mild symptoms compared with the 1918 pandemic (the "Spanish flu") that resulted in the death of 50 million people (2).

\section{Vaccines}

\section{Conventional vaccines}

Conventional vaccines-live attenuated or inactivated-have proved to be beneficial against a number of infectious diseases in the past. However, they may not always be suitable for use in outbreak situations, as they bear the risk of reversion and are capable of causing severe adverse effects, making this approach unfavourable for highly pathogenic organisms. This reversion was seen with the Ebola vaccine (3). Furthermore, conventional vaccines pose challenges with commercial production, as they require whole pathogen cultivation and propagation, which require the use of biosafety level labs. 
As these viruses are largely uncharacterized before an outbreak occurs, time becomes a crucial factor for effective vaccine development. Currently, the average development time for conventional vaccines from preclinical stage is more than 10 years (4), underscoring the urgent need to explore methods that allow expeditious development-to prevent an emerging outbreak from becoming a pandemic.

\section{Viral vector-based vaccines}

A valuable alternative to a conventional vaccine is a viral vector-based vaccine, as this technique represents a highly versatile platform. The viral vectors can be exploited to encode for heterologous antigens that can be delivered into the host cells. Inside the host they express the encoded antigens, prompting the host to induce an immune response. This platform appeared to be effective against the Ebola virus, and rVSV ZEROV currently represents the most promising candidate for a licensed vaccine (5). However, viral vectors are not widely used as they are considered potential risks to human health and environment because they are genetically modified organisms (GMOs). Moreover, these vectors always bear the risk of integration into the host genome, and too high or persistent replication in the host raises concerns for their use in humans (6).

\section{Nucleic acid vaccines}

Nucleic acid vaccines, both deoxyribonucleic acid (DNA) and ribonucleic acid (RNA) vaccines, come with potential benefits over conventional vaccines, as they are more stable, are more cost-effective, are easy to manufacture and handle, provide broad-spectrum immunity (meaning a multi-antigen vaccine can be designed that can effectively target constantly evolving strains of viruses) and can induce both humoral and cellular immune responses $(7,8)$. Nucleic acid vaccines also have an edge over the viral-vector-based vaccines because they are derived from recombinant plasmids of bacterial origin, and persistent replication and host genome integration, though a possibility, have remain a low risk $(9,10)$. Furthermore, the United States Food and Drug Administration has recommended that the termination of a study is not required if plasmid DNA remains below 30,000 copies per $\mu \mathrm{g}$ of host DNA in host tissues (11).

The DNA vaccines against Middle East respiratory syndrome coronavirus (MERS-CoV) showed promising results in preclinical trial and thereafter entered the phase I clinical trial. However, the vaccines did not progress further, mainly because this illness is characterized by a changing epidemiology; meaning that by the time the vaccine candidate entered into clinical trial, the incidence of the disease had significantly declined, presenting a potential barrier for an efficacy trial (12). In 2016, during the Zika crisis, a preclinical study conducted in non-human primates using a vaccine containing DNA constructs that expressed precursor membrane and envelope (prM-E) protein of the virus demonstrated correlation of antibody levels and protection. With this success, a phase I clinical study was initiated and preliminary results showed that the vaccine was safe and induced neutralizing antibodies in $62 \%$ of the participants (13).
Importantly, this initiative was undertaken soon after the DNA sequences of the virus antigens were decoded, indicating the speed with which DNA vaccines can be produced.

In the spring of 2009, with the novel H1N1 influenza becoming a global pandemic, a phase I clinical trial was initiated. By August 2009, using a DNA-based approach encoding the hemagglutinin protein of A/California/04/2009 (H1N1pdm09) was developed. Although the DNA vaccine was able to generate hemagglutination inhibition antibody titres in only $30 \%$ of the subjects, the titres were increased to $72 \%$ within four weeks after boosting with a licensed conventional influenza vaccine. These data suggested that the virus can be controlled by employing DNA as an initial priming agent, followed by boosting with a conventional vaccine (14). A vaccine against HIV had been difficult to develop due to the changing nature of the virus. Of the six HIV-1 vaccine efficacy trials to date, only one (RV144) performed well and entered the phase III efficacy trial. Development of this vaccine was achieved after several hits-and-misses by adopting a stratagem of priming with DNA constructs expressing clade C gp120 and clade B gp41, gap and protease proteins and boosting with bivalent subtype C gp120 protein complex of the virus (15).

The RNA vaccine (using messenger RNA; mRNA) appears to have certain benefits over its DNA and viral-vector counterparts. As mRNA does not interact with the host-cell DNA, mRNA vaccines are free from the potential risk of integration into the host genome. Furthermore, mRNA vaccines have a simple vector structure containing an open reading frame (ORF) encoding the target antigen flanked by specific regulatory genes and thus are not capable of inducing anti-vector immunity (16). Currently, mRNA vaccines against Zika, Chikungunya and certain strains of influenza virus are undergoing phase I clinical trials (11).

\section{Coronavirus-specific issues}

Coronaviruses are single-stranded positive-sense RNA viruses. These viruses are of four genera (alpha, beta, gamma and delta coronaviruses); SARS-CoV-2 is a beta coronavirus. It consists of four structural proteins, namely spike, envelope, membrane and nucleocapsid, that are believed to be involved in invading the host cells. Although studies are still underway to better understand the biology of SARS-CoV-2, there has been an array of vaccine candidates launched into clinical testing and some have already been approved for use worldwide. The vaccines developed by Pfizer, AstraZeneca and Moderna are shown to be effective in the $90 \%$ range and interestingly they are nucleic acid vaccines. Despite the widespread use of these vaccines, some critical questions still need to be addressed: 1) are neutralizing antibodies and a SARS-CoV-2-specific T cell response sufficient to prevent the disease and subsequent spread; 2) how long does the protective immunity last following infection or vaccination; 3) what are the factors responsible for dysregulated immune response in patients with severe symptoms; and 4) does the 
vaccine cause any severe adverse reactions. So far, none of the approved COVID-19 vaccines have shown any serious safety concerns; however, there are lingering questions around their safety with long-term use and will they be effective against the variant strains of SARS-CoV-2. Typically, when a vaccine is approved for use by the general public, it goes through stringent safety assessments to detect problems by testing it in tens of thousands of study participants, studies that span several years. Apparently, this did not happen with the COVID-19 vaccines; these vaccines went on clinical trials with small sample sizes of participants and in less than a year the vaccines were approved for use in humans. This was done because we were in the midst of a global pandemic and controlling the virus was an urgent necessity; thus, leaving some safety and effectiveness issues to be addressed mainly via post-marketing studies.

Going forward, whether it is with a modification of the currently approved COVID-19 vaccines or with a new COVID-19 vaccine, it is prudent to consider the developmental challenges faced by other viral vaccines in developing COVID-19 vaccines. A multifaceted approach, such as the prime-boost stratagem that was used for the influenza and HIV vaccines or directions derived from preclinical studies, would be worthwhile to explore. For instance, in a recent preclinical study (17), six DNA constructs expressing different forms of SARS-CoV-2 spike proteins were used to vaccinate rhesus macaques. The macaques exhibited both humoral and cellular immune responses and a significant reduction in viral loads upon challenge with SARS-CoV-2 following vaccination. Although the sample size was small $(n=4)$ for each of the vaccine candidate groups, the study did hint that neutralizing antibodies and antibody-dependent complement deposition could be useful benchmarks to study while developing vaccine against SARS-CoV-2.

\section{Conclusion}

Time is of the essence in controlling pandemics, but the efficacy and safety of any vaccine are also fundamental. Notably, when designing a vaccine against viral infection, it is essential to look at which approaches worked and which did not work with other viral vaccines.

\section{Author's statement}

$\mathrm{RC}$ conceived and wrote the manuscript

\section{Competing interests}

None.

\section{Funding}

None.

\section{References}

1. Heath Kelly. The classical definition of a pandemic is not elusive. Bulletin of the World Health Organization 2011;89:540-541. DOI

2. Johnson NP, Mueller J. Updating the accounts: global mortality of the 1918-1920 "Spanish" influenza pandemic. Bull Hist Med 2002;76(1):105-15. DOI PubMed

3. Richardson JS, Dekker JD, Croyle MA, Kobinger GP. Recent advances in Ebolavirus vaccine development. Hum Vaccin 2010;6(6):439-49. DOI PubMed

4. Pronker ES, Weenen TC, Commandeur H, Claassen EH, Osterhaus AD. Risk in vaccine research and development quantified. PLoS One 2013;8(3):e57755. DOI PubMed

5. Regules JA, Beigel JH, Paolino KM, Voell J, Castellano AR, Hu Z, Muñoz P, Moon JE, Ruck RC, Bennett JW, Twomey PS, Gutiérrez RL, Remich SA, Hack HR, Wisniewski ML, Josleyn MD, Kwilas SA, Van Deusen N, Mbaya OT, Zhou Y, Stanley DA, Jing W, Smith KS, Shi M, Ledgerwood JE, Graham BS, Sullivan NJ, Jagodzinski LL, Peel SA, Alimonti JB, Hooper JW, Silvera PM, Martin BK, Monath TP, Ramsey WJ, Link CJ, Lane HC, Michael NL, Davey RT Jr, Thomas SJ; rVSV $\triangle$ G-ZEBOV-GP Study Group. A recombinant vesicular stomatitis virus Ebola vaccine. $N$ Engl J Med 2017;376(4):330-41. DOI PubMed

6. Baldo A, van den Akker E, Bergmans HE, Lim F, Pauwels K. General considerations on the biosafety of virus-derived vectors used in gene therapy and vaccination. Curr Gene Ther 2013;13(6):385-94. DOI PubMed

7. Prazeres DM, Monteiro GA. Plasmid Biopharmaceuticals. Microbiol Spectr 2014 Dec;2(6):1-18. DOl PubMed

8. Maslow JN. Vaccines for emerging infectious diseases: lessons from MERS coronavirus and Zika virus. Hum Vaccin Immunother 2017;13(12):2918-30. DOI PubMed

9. Hu Y, Li W, Gao T, Cui Y, Jin Y, Li P, Ma Q, Liu X, Cao C. The severe acute respiratory syndrome coronavirus nucleocapsid inhibits type I interferon production by interfering with TRIM25-mediated RIG-I ubiquitination. J Virol. 2017;91:e02143-16. DOI PubMed

10. Huang $C$, Wang $Y$, Li $X$, Ren $L$, Zhao J, Hu Y, Zhang L, Fan G, Xu J, Gu X, Cheng Z, Yu T, Xia J, Wei Y, Wu W, Xie X, Yin W, Li H, Liu M, Xiao Y, Gao H, Guo L, Xie J, Wang G, Jiang R, Gao Z, Jin Q, Wang J, Cao B. Clinical features of patients infected with 2019 novel coronavirus in Wuhan, China. Lancet 2020;395(10223):497-506. DOI PubMed 
11. Sariol A, Perlman S. Lessons for COVID-19 Immunity from other coronavirus infections. Immunity 2020;53(2):248-63. DOI PubMed

12. Diamond MS, Pierson TC. The challenges of vaccine development against a new virus during a pandemic. Cell Host Microbe 2020;27(5):699-703. DOl PubMed

13. Kiambi S, Corman VM, Sitawa R, Githinji J, Ngoci J, Ozomata AS, Gardner E, von Dobschuetz S, Morzaria S, Kimutai J, Schroeder S, Njagi O, Simpkin P, Rugalema G, Tadesse Z, Lubroth J, Makonnen Y, Drosten C, Müller MA, Fasina FO. Detection of distinct MERS-Coronavirus strains in dromedary camels from Kenya, 2017. Emerg Microbes Infect 2018;7(1):1-4. DOI PubMed

14. Josset L, Menachery VD, Gralinski LE, Agnihothram S, Sova P, Carter VS, Yount BL, Graham RL, Baric RS, Katze MG. Cell host response to infection with novel human coronavirus EMC predicts potential antivirals and important differences with SARS coronavirus. MBio 2013;4(3):e00165-13.

DOI PubMed

15. Hsu DC, O'Connell RJ. Progress in HIV vaccine development. Hum Vaccin Immunother 2017 May;13(5):1018-30.

DOI PubMed
16. Shaman J and Glanti M. Direct measurement of rates of asymptomatic infection and clinical care-seeking for seasonal coronavirus, MedRxiv. 2020;2020.01.30.20019612. https://www.medrxiv.org/content/10.1101/2020.01.30.2001 9612v1.full.pdf

17. Yu J, Tostanoski LH, Peter L, Mercado NB, McMahan K, Mahrokhian SH, Nkolola JP, Liu J, Li Z, Chandrashekar A, Martinez DR, Loos C, Atyeo C, Fischinger S, Burke JS, Slein MD, Chen Y, Zuiani A, Lelis FJ, Travers M, Habibi S, Pessaint L, Van Ry A, Blade K, Brown R, Cook A, Finneyfrock B, Dodson A, Teow E, Velasco J, Zahn R, Wegmann F, Bondzie EA, Dagotto G, Gebre MS, He X, Jacob-Dolan C, Kirilova M, Kordana N, Lin Z, Maxfield LF, Nampanya F, Nityanandam R, Ventura JD, Wan H, Cai Y, Chen B, Schmidt AG, Wesemann DR, Baric RS, Alter G, Andersen $\mathrm{H}$, Lewis MG, Barouch DH. DNA vaccine protection against SARS-CoV-2 in rhesus macaques. Science 2020;369(6505):806-11. DOI PubMed 